\title{
POR UMA MULTILATERALIZAÇÃO DO REGIONALISMO E ALÉM: NOVOS DESAFIOS E PERSPECTIVAS DA RELAÇÃO ENTRE A OMC E OS ACORDOS REGIONAIS
}

\author{
MULTILATERALIZING REGIONALISM AND BEYOND: NEW CHALLENGES AND PERSPECTIVES \\ OF THE RELATIONSHIP BETWEEN THE WTO AND REGIONAL AGREEMENTS
}

Camilla Capucio $^{*}$

\begin{abstract}
Resumo:
Uma vez superada a dicotomia da relação de antagonismo ou complementariedade entre o sistema multilateral de comércio e o regionalismo, resta clara a necessidade de uma nova abordagem da temática. Diante de novas características do regionalismo e do comércio internacional no século XXI, que o trabalho explora algumas das novas perspectivas, com especial atenção à proposta de "multilateralização do regionalismo", e as condições de sua concretização.

Palavras-chave: Regionalismo. Acordos Regionais de Comércio. OMC. Sistema Multilateral de Comércio. Multilateralização do Regionalismo.
\end{abstract}

\begin{abstract}
:
Once surpassed the dichotomy of the relationship of antagonism or complementarity between the multilateral trading system and the regionalism, there is a clear need for a new approach to the subject. Faced with new features of regionalism and international trade in the twenty-first century, the paper explores some of the new perspectives, with special attention to the proposal of "multilateralizing regionalism", and the conditions for its realization.
\end{abstract}

Keywords: Regionalism. Regional Trade Agreements. WTO. Multilateral Trade System. Multilateralization of Regionalism.

1. Introdução da temática: A OMC e os Blocos Regionais

Embora o regionalismo fosse existente já à época do GATT - 1947, a proliferação dos blocos regionais é fenômeno que se relaciona diretamente com as modificações da sociedade internacional nas últimas décadas do século XX. A nova conformação das forças políticas após a queda do Muro de Berlim trouxe mudanças que propiciaram a ascensão dos blocos regionais como alternativa à satisfação de interesses

\footnotetext{
* Doutoranda pela Faculdade de Direito da Universidade de São Paulo. Membro do Núcleo de Estudos em Tribunais Internacionais (NETI-USP). Mestre em Direito Internacional Econômico pela Universidade Federal de Minas Gerais. Correio eletrônico: ccapucio@usp.br.
} 
de atores no interior dos Estados, diante da força centrípeta da globalização e as forças centrífugas da fragmentação. ${ }^{1}$

A nova configuração do cenário internacional significou uma alteração substancial nos paradigmas econômico, comercial, político e social, afetando intensamente a estrutura e o papel do Estado-nação, que ao perder sua centralidade tradicional enquanto unidade privilegiada de condução ou controle dos fluxos de pessoas, bens, capitais ou ideias, ${ }^{2}$ se mostra então insuficiente para responder às novas necessidades da sociedade internacional. $^{3}$

O regionalismo tem abarcado, desde sua origem, diferentes modos de institucionalização, de acordo com os interesses dos Estados participantes na integração, e esta diversidade tem se manifestado de forma marcante na atualidade. ${ }^{4}$ A complexidade da temática consiste na dimensão política do processo de integração, que não pode ser dissociada dos aspectos jurídico e econômico, vez que a estratégia e o nível de aprofundamento dependem necessariamente da vontade política dos Estados que decidem se aproximar. ${ }^{5}$

A partir da década de 80 , contudo, o fenômeno do regionalismo tem tomado não apenas novo fôlego, mas nova configuração. ${ }^{6} \mathrm{O}$ novo regionalismo se diferencia substancialmente, por ultrapassar a pauta das questões tarifárias, incorporando novas temáticas ${ }^{7}$ e relacionando-se com a mudança na geografia do poder mundial em sentido mais amplo.

Por um lado, o novo regionalismo é identificado, de modo geral, com o regionalismo aberto, por sua interação com o mercado exterior e com a liberalização multilateral. ${ }^{8}$ Sob tal perspectiva haveria uma tendência de conjugação dos ARC com a abertura econômica multilateral, ${ }^{9}$ como mecanismo mediante o qual os governos

1 LAFER, Celso. Comércio, desarmamento e direitos humanos: reflexões sobre uma experiência diplomática. São Paulo: Paz e Terra, 1999. p. 33.

2 SANTOS, Boaventura de Sousa. Os processos da globalização. In: SANTOS, Boaventura de Sousa. Globalização: fatalidade ou utopia? Porto: Edições Afrontamento, 2001. p. 42.

3 SILVA, Roberto Luiz. Direito comunitário e da integração. Porto Alegre: Ed. Síntese, 1999. p. 23.

4 AMARAL JÚNIOR, Alberto do. A solução de controvérsias na OMC. São Paulo: Atlas, 2008. p. 29.

5 CELLI JUNIOR, Umberto. Teoria geral da integração: em busca de um modelo alternativo. In: MERCADANTE, Araminta de Azevedo; JUNIOR, Umberto Celli; ARAÚJO, Leandro Rocha de. Blocos econômicos e integração na América Latina, África e Ásia. Curitiba: Juruá, 2003. p. 19.

6 HURRELL, Andrew. On global order: power, values and the Constitution of International Society. New York: Oxford University Press, 2007. p. 241; FAWCETT, Louise. Regionalism in Historical Perspective. In: FAWCETT, Louise; HURRELL, Andrew. Regionalism in World Politics. Oxford: Oxford University Press, 1995. p. 9.

7 HORN, Henrik; MAVROIDIS, Petros C.; SAPIR, André. Beyond the WTO? An anatomy of EU and US preferential trade agreements. Bruegel Blueprint Series, v. VII. Brussels: Bruegel, 2009.

$8 \quad$ PRAZERES, Tatiana Lacerda. A OMC e os Blocos Regionais. São Paulo: Aduaneiras, 2008. p. 150-151.

9 DEVLIN, Robert; ESTEVADEORDAL, Antoni. What's New in the New Regionalism in the Americas? In: BULMER-THOMAS. Victor. (ed). Regional Integration in Latin America and the Caribbean: The Political 
conduziriam sua inserção econômica mantendo relativa autonomia política. ${ }^{10}$ Por outro lado, contudo, a nova agenda do regionalismo, bem como a sua arquitetura diferenciada, trouxe novas complexidades ao seu relacionamento com o sistema multilateral de comércio.

Assim, sob a nomenclatura de Acordos Regionais de Comércio (ARC), ou Acordos Preferenciais de Comércio (APC), a recente onda de regionalismo em face do sistema multilateral apresenta quatro tendências principais: (i) o protagonismo desses Acordos nas políticas comerciais da maior parte dos Estados, superando a primazia do sistema multilateral; (ii) o crescente nível de sofisticação, nas áreas de normatividade e nos parceiros não necessariamente em contiguidade geográfica; (iii) o aumento dos acordos Norte-Sul, entre países desenvolvidos e em desenvolvimento; (iv) expansão e consolidação de um crescente número de ARC bilaterais entre blocos regionais de comércio de dimensão continental, com aparente função de acesso estratégico à mercados. ${ }^{11}$

Não é recente a preocupação de estudiosos com o futuro do sistema multilateral, face à proliferação dos Acordos Regionais. A percepção, entretanto, de que a formação de tais acordos tem se dado de forma livre e com regulamentação pouco efetiva, têm levado a doutrina a vislumbrar uma inversão nas relações econômicas internacionais, na qual o regionalismo perde seu caráter de exceção, constituindo uma regra, em potencial ameaça ao multilateralismo, exigindo mudanças dos Estados e/ou do sistema multilateral. ${ }^{12}$

A fraca disciplina do tema, a dificuldade em se atingir um consenso, e o interesse individual de parte dos Estados em deixar a questão livre de impedimentos nas relações internacionais, contribuem para a erosão da não-discriminação no comércio internacional, bem como apontam para um risco de imposição assimétrica das regras do comércio internacional, como discutiremos adiante.

\section{A dicotomia superada: stumbling blocs e building blocs}

Em uma visão global da literatura nesta temática, é possível reconhecer uma evolução, de modo correlato às ondas de acordos regionais de comércio, consubstanciada

Economy of Open Regionalism. London: Institute of Latin American Studies, University of London, 2001 p. 22.

10 CEPAL. Capítulo VII Regionalismo Abierto: un Examen del Concepto a la Luz de las Experiencias de América Latina y Asia y el Pacífico. In: Panorama de la Inserción internacional de América Latina y el Caribe. LC/G.2085-P. Santiago: Naciones Unidas, 2001. p. 208.

11 FIORENTINO, Roberto; VERDEJA, Luis; TOQUEBOEUF, Christelle. The Changing Landscape of Regional Trade Agreements: 2006 Update. WTO Discussion Paper n. 12. Geneva: WTO, 2007

12 O relatório foi elaborado pelo conjunto de autores de peso formado por Peter SUTHERLAND, Jagdish BHAGWATI, Kwesi BOTCHWEY, Niall FITZGERALD, Koichi HAMADA, John JACKSON, Celso LAFER e Thierry DE MONTBRIAL. 
em três gerações distintas na doutrina. ${ }^{13}$ A primeira geração corresponde aos estudos originados a partir de VINER, ${ }^{14}$ que elabora os conceitos de criação de comércio (trade creation) e desvio de comércio (trade divertion), que compõem uma análise econômica dos efeitos dos acordos regionais face à liberalização multilateral. $\mathrm{O}$ teste do desvio e criação de comércio formulado nesta primeira geração continua como ponto de partida relevante da análise dos efeitos econômicos da formação de blocos, embora as críticas e refinamentos tenham levado à uma análise dos efeitos em uma perspectiva mais ampla pelos estudos que se seguiram. ${ }^{15}$

A segunda geração de estudos nesta temática polarizou a discussão entre a identificação desses acordos como blocos de contenção stumbling blocs da liberalização do comércio multilateral, em uma relação de antagonismo, a percepção dos acordos regionais de comércio como building blocs, em complementariedade ao sistema multilateral. Essa dicotomia, embora tenha partido da geração passada dos estudos econômicos, incorporou à discussão outros fatores não diretamente econômicos.

Sob o ponto de vista da tensão entre os Acordos Regionais e a OMC, criticam-se os efeitos do que BHAGWATI denominou spaguetti bowl, ${ }^{16} \mathrm{em}$ referência ao emaranhado de regulamentações comerciais sobrepostas e inconsistentes entre si, que ameaçaria a transparência e a previsibilidade no comércio internacional, e resultaria no aumento dos custos de transação através dessa complexa arquitetura.

Ademais, afirma-se que os ARC podem desviar a atenção das negociações multilaterais, por motivos de recursos financeiros e humanos limitados destinados a negociações comerciais, e por razão de mudança de foco e perda de interesse político no sistema multilateral. ${ }^{17}$ A primeira hipótese é claramente o caso de países menos desenvolvidos, que não detêm corpo diplomático e recursos materiais suficientes para a participação simultânea em negociações regionais e multilaterais. A segunda hipótese se confunde com a observada perda de interesse de certos países no avanço das negociações multilaterais, resultado também dos entraves ainda não solucionados da Rodada de Doha.

Por fim, alega-se que o tratamento de temas "sensíveis" pelos sistemas regionais poderia prejudicar o consenso nas regras do comércio unilateral, por antecipar a

13 THORSTENSEN, Vera. O Multissistema da Regulação do Comércio Global: Proposta de novo referencial teórico e nova metodologia de análise. Revista Tempo do Mundo/ Instituto de Pesquisa Econômica Aplicada. v. 3, n. 1. Brasília, IPEA, 2011. p. 89-115.

14 VINER, Jacob. The Customs Union Issue. Washington DC: Anderson Kramer Associates, 1961. p. 44.

15 MANSFIELD, Edward D.; MILNER, Helen V. The Political Economy of Regionalism. New York: Columbia University Press, 1997. p. 22 e ss.

16 BHAGWATI, Jagdish. Preferential Trade Agreements: the Wrong Road. Law and Policy in International Business. v. 27, p. 865-90, 1996.

17 FIORENTINO, Roberto; VERDEJA, Luis; TOQUEBOEUF, Christelle. op. cit., p. 11. 
percepção das dificuldades geradas por meio da adoção regional de regras em temas não diretamente comerciais (non trade issues).

Por outro lado, sob a perspectiva da compatibilidade entre os acordos regionais o sistema multilateral, afirma-se que os Acordos Regionais, devido ao número reduzido de participantes, conseguiriam alcançar liberalizações mais profundas que o sistema de negociações multilaterais. Assim, ao promoverem a liberalização regional, afirma-se que os Acordos Regionais favorecem o caminho ao livre comércio, objetivo basilar do sistema multilateral.

Ademais, como antecipado, os arranjos regionais com frequência aprofundam os compromissos já acordados, ou incluem compromissos em áreas ainda não abrangidas pelas obrigações da OMC. O estabelecimento de compromissos mais profundos- WTO-plus, ${ }^{18}$ e de compromissos que ultrapassam as áreas atualmente disciplinadas- WTO-extra, ${ }^{19}$ ao mesmo tempo em que são apresentados por alguns como prejudiciais ao consenso na $\mathrm{OMC}$, pois escancaram as dificuldades de implementação e malefícios por parte dos países em desenvolvimento, são também interpretados como antecedentes positivos às negociações multilaterais. ${ }^{20}$

A perspectiva nesse ponto parte da ideia de que os compromissos regionais representam consensos parciais entre os membros da $\mathrm{OMC}$, oferecendo precedente útil às negociações multilaterais, também através da formação de alianças e fortalecimento das relações entre parceiros comerciais. Embora haja a possibilidade, em temas como direitos trabalhistas e meio ambiente, de regulamentações divergentes e discriminatórias a partir da multiplicidade de arranjos regionais, as demandas do mercado e os custos da aplicação de diversas regulamentações diferentes empurrariam os membros para a convergência, através da harmonização e unificação das regras. ${ }^{21}$

Além do importante precedente ao consenso, o tratamento pelos Acordos Regionais de temas além das obrigações da OMC oferece experiências concretas de implementação que podem auxiliar o sistema multilateral a regulamentar esses temas de maneira "menos traumática" aos Estados. Nesse aspecto, os Acordos Regionais funcionariam como uma "sala de aula" no mundo real, na qual a negociação e implementação de regras em temas “sensíveis” poderia ensinar aos negociadores, expondo o melhor caminho para a inclusão desses novos temas na agenda da OMC.

\footnotetext{
18 A expressão WTO-plus é utilizada na doutrina em referência a Acordos que tratam de temas previstos na OMC, mas estabelecem compromissos mais onerosos que a disciplina do sistema multilateral.

19 A expressão WTO-extra é utilizada na doutrina em referência a Acordos que tratam de temas ainda não disciplinados pelo sistema multilateral.

20 CEPAL. op. cit., p. 210.

21 FIORENTINO, Roberto; VERDEJA, Luis; TOQUEBOEUF, Christelle. op. cit., p. 8.
} 
Em superação desta dicotomia, a geração atual de estudos concentra no aspecto concreto e real da temática, propondo análises específicas dos principais Acordos Regionais existentes, exames de compatibilidade de regras determinadas com a normativa multilateral, e mecanismos concretos de multilateralização das regras regionais. Focaremos em especial nesta última categoria, sob o marco teórico da "multilateralização do regionalismo".

A superação da dicotomia clássica por esta nova geração de estudos é resultado, pois, de mudanças concretas na arquitetura das relações econômicas internacionais observadas nos últimos anos. ${ }^{22}$ Não se pode ignorar, ainda, que a recente crise econômica mundial, e o fracasso nas negociações de novos compromissos na OMC, tem dado combustível adicional à conclusão de Acordos Regionais pelos principais atores das relações internacionais. Esse quadro acaba por extremar as previsões, levando à percepção de objetivos implícitos de exportação de um modelo regulatório na conclusão de pacotes de Acordos Regionais, e inclusive a perspectivas "apocalípticas" do futuro da OMC.

\section{A disciplina da OMC sobre os Acordos Regionais}

Embora fuja do escopo deste trabalho adentrar detalhadamente na disciplina normativa dos Acordos Regionais no sistema multilateral, não se pode prescindir da menção, ainda que breve, dos elementos que a constituem.

Dentro da categoria Acordos Regionais de Comércio, gênero mais amplo, podem ser encontrados os seguintes tipos de Acordos Regionais disciplinados pela OMC: (1) as Uniões Aduaneiras (Custom Unions); (2) as Áreas de Livre Comércio (Free Trade Areas); (3) os Acordos provisórios que objetivem a formação de uma União Aduaneira ou de uma Área de Livre Comércio; (4) os Acordos de escopo parcial (Partial Scope Agreements) - possíveis apenas aos países em desenvolvimento.

O princípio da nação mais favorecida é basilar ao sistema multilateral de comércio, pois consubstancia a obrigação de estender concessões acordadas separadamente aos demais membros, ${ }^{23}$ desestimulando a discriminação e levando os membros a negociarem em uma matriz multilateral. A formação dos Acordos Regionais, contudo, é uma exceção prevista no Artigo XXIV do GATT, que encontra correspondência no Artigo V do GATS.

\footnotetext{
22 BALDWIN, Richard. 21th Century Regionalism: Filling the gap between 21th century trade and 20th century rules. World Trade Organization, Economic Research and Statistics Division. Staff Working Paper ERSD-2011-08, mai. 2011.

23 JACKSON, Jonh H. The jurisprudence of GATT and the WTO. Cambridge: Cambridge University Press, 2000. p. 59.
} 
Os requisitos específicos para que um Acordo Regional seja considerado compatível com a disciplina do GATT são (1) transparência; (2) compromisso com a profunda liberalização comercial no interior do bloco - liberalização de "substancialmente todo o comércio" e (3) neutralidade em face do comércio dos Estados que não façam parte do bloco. ${ }^{24 / 25}$ Tais critérios advém da leitura dos parágrafos 7,8 e 5/6 do Artigo XXIV GATT, respectivamente. Visando esclarecer alguns pontos então obscuros, vez que a redação do Artigo permanece a mesma desde 1947, foi formulado o Entendimento sobre a Interpretação do Artigo XXIV, que embora ainda deixe questões em aberto, ao não oferecer um parâmetro interpretativo substancial, lança luz sobre certas questões, de natureza procedimental. ${ }^{26}$

$\mathrm{O}$ artigo V do GATS impõe três requisitos específicos: (1) transparência; (2) compromisso com a liberalização efetiva no interior do bloco, requisito que se consubstancia nas obrigações de (2.a) ter uma cobertura setorial substancial e (2.b) estabelecer a ausência ou eliminação, no essencial, de toda discriminação entre as partes em setores sujeitos a compromissos multilaterais; e (3) neutralidade em face do comércio de serviços nos respectivos setores e sub-setores em relação a terceiros Estados. Tais critérios advém da leitura dos parágrafos 7,1 e 4 do art. V do GATS, respectivamente. ${ }^{27}$

Há, ainda, a Cláusula de Habilitação, nome pelo qual ficou conhecido o mecanismo previsto na Decisão de 28 de Novembro de 1979 L/4903 - 1979 Differential and More Favourable Treatment, Reciprocity and Fuller Participation of Developing Countries $^{28}$ - prevê condições mais favoráveis aos países em desenvolvimento para a formação de arranjos regionais entre si, relativos ao comércio de bens. ${ }^{29}$

O Comitê de Acordos Regionais foi criado em 1996, com o objetivo principal de centralizar o exame de conformidade dos Acordos notificados com as regras da OMC, além de analisar a questão do regionalismo sob uma perspectiva sistêmica.

${ }_{24}$ GATT. Versão oficial em português dada pelo Decreto Legislativo n. 1.355, de 30 de Dezembro de 1994. Disponível em: <http://www.planalto.gov.br/ccivil_03/decreto/Antigos/D1355.htm>. Acesso em: 30 jun. 2013.

25 FIORENTINO, Roberto; VERDEJA, Luis; TOQUEBOEUF, Christelle. op. cit.

${ }^{26}$ Entendimento sobre a Interpretação do Artigo XXIV. Versão oficial em português dada pelo Decreto Legislativo n. 1.355, de 30 de Dezembro de 1994. Disponível em: <http://www.planalto.gov.br/ccivil_03/ decreto/Antigos/D1355.htm>. Acesso em: 30 jun. 2013.

27 GATS. Versão oficial em português dada pelo Decreto Legislativo n. 1.355, de 30 de Dezembro de 1994. Disponível em: <http://www.planalto.gov.br/ccivil_03/decreto/Antigos/D1355.htm>. Acesso em: 30 jun. 2013.

28 WTO. Differential and more favourable treatment, reciprocity and fuller participation of developing countries. L/4903 - 1979. Decisão de 28 de Novembro de 1979.

29 Cf: CELLI JUNIOR, Umberto et al. MERCOSUR in South-South Agreements: In the middle of two models of regionalism. UNCTAD Virtual Institute, USP - FLACSO Joint Research Project Analysis of South-South Cooperation in Trade, set. 2010. Disponível em: <http://www.iadb.org/intal/intalcdi/PE/2011/08164.pdf>. Acesso em: 30 jun. 2013. 
Apesar de seus amplos poderes, contudo, este Comitê não tem sido capaz de contribuir de maneira eficaz para a aplicação e clarificação das regras multilaterais que regem o regionalismo, ${ }^{30}$ haja vista a impossibilidade de consenso entre os membros acerca do exame de compatibilidade, do exame documental e da prática do Comitê. ${ }^{31} \mathrm{E}$ a ausência de consenso, manifestada exatamente por meio da adoção de relatórios inconclusivos, expressa uma discordância de fundo em relação ao papel que deve ser desempenhado pela OMC face ao emaranhado de Acordos Regionais.

$\mathrm{Na}$ atualidade, contudo, o foco principal se afasta um pouco da análise da efetividade do exame de compatibilidade, alcançando a necessidade de uma revisão substancial desta disciplina normativa como um todo, de modo a preencher o espaço existente entre o regionalismo do século XXI e as regras do século XX. ${ }^{32}$ Por suas características únicas, o regionalismo deste século não se adéqua à antiguidade da formulação das regras existentes.

Como bem destaca Baldwin, a revolução tecnológica-informacionalcomunicacional promoveu uma real internacionalização das cadeias produtivas, que trouxe a imbricação entre (i) comércio; (ii) investimentos e (iii) serviços ao centro do comércio internacional. Essa nova configuração exige normas complexas para sua regulação, que abarquem essas temáticas. ${ }^{33}$

\section{A multilateralização do regionalismo}

Em Julho de 2006, Richard Baldwin apresentou na World Economy Annual Lecture trabalho denominado Multilateralizing Regionalism: Spaguetti bowls as building blocs on the path to Free Trade, posteriormente publicado em diversas revistas especializadas. Referido trabalho, segundo o autor resultado de suas pesquisas desenvolvidas desde a década de 1980 , propõe uma nova abordagem da relação entre o sistema multilateral e o regionalismo. ${ }^{34}$

Essa nova abordagem parte da premissa de que, haja vista o vertiginoso alastramento dos Acordos Regionais de Comércio nos últimos anos, e o papel central de blocos consolidados como a União Europeia, Mercosul, NAFTA e APEC na economia internacional, o fenômeno do regionalismo é realidade das relações internacionais, que

30 MAVROIDIS, Petros. If You Don't Do Someone Else Will (or Won’t): Testing Compliance of Preferential Trade Agreements with the Multilateral Rules. Journal of World Trade. V. 40, n. 1, p. 187-214, 2006.

31 PRAZERES, Tatiana Lacerda. op. cit.

32 BALDWIN, Richard. op. cit.

33 BALDWIN, Richard. op. cit. p. 5.

34 BALDWIN, Richard. Multilateralizing Regionalism: Spaguetti Bowls as Building Blocs on the Path to Global Free Trade. The World Economy. v. 29, n. 11, p. 1451-1518, 2006. 
não pode ser negado ou evitado, mas deve ser melhor aproveitado para a geração de benefícios em processos multilaterais.

Assim, uma vez ultrapassada a tradicional oposição "regionalismo versus multilateralismo", Baldwin suscita a necessidade de implementação de um novo paradigma de "regionalismo multilateralizante", cuja agilidade na harmonização de regras e obtenção de resultados compartilhados pelos Estados-membros seja capaz de fortalecer e aprofundar a liberalização multilateral do comércio. $\mathrm{O}$ autor pretende, portanto, desenvolver estratégias para a multilateralização do regionalismo existente e emergente, haja vista que parte dos teóricos se perdeu na discussão do dualismo entre os blocos regionais e a OMC.

O autor desenvolveu um modelo econômico para comprovar que os efeitos de um Acordo Regional sob a economia de Estados não membros tende à levá-los também à uma adesão ao Acordo ou à liberalizações regionais próprias. A partir deste modelo, reafirma o efeito em cadeia da formação dos blocos de integração, e faz uma prospecção de que o cenário internacional em 2010 consistiria na existência de três grandes blocos polarizadores de emaranhados de Acordos Regionais, unilaterais e multilaterais, situados na Europa, Ásia e América do Norte. ${ }^{35}$

Como forma de densificar os compromissos comerciais existentes nesses grandes blocos, o autor propõe, como medidas multilateralizantes, medidas que promovam uma harmonização das regras de setores do comércio internacional, a partir de arranjos regionais já existentes. O emaranhado de obrigações comerciais, denominado de síndrome do spaghetti bowl, se traduz concretamente em duas características básicas e inter-relacionadas: (1) regras de origem diferentes e não-harmonizadas, e (2) cumulação bilateral. ${ }^{36}$ Será, portanto, sob esses dois elementos que deverão recair as medidas multilateralizantes, tendentes a "domar" o emaranhado de acordos.

\subsection{Regras de origem e cumulação}

No que tange ao primeiro elemento, é explícita a relevância das regras de origem, essenciais à toda a dinâmica preferencial dos arranjos regionais, vez que são elas que distinguem entre produtos originados em Estados membros dos produtos originados em Estados não-membros. Regras de origem são instrumentos de determinação da origem de bens para fins de aplicação tarifária em um determinado território, objetivando,

$35 \quad$ BALDWIN, Richard. op. cit. nota 34.

36 É frequente também o uso da palavra acumulação para designar exatamente o mesmo mecanismo que explicamos no trabalho. 
portanto, evitar que preferências ou restrições devidas ao comércio de um bem sejam burladas através da adulteração da origem do produto importado. ${ }^{37}$

A regras de origem têm sido uma preocupação primária dos autores, negociadores e participantes do comércio internacional, vez que costumam funcionar como instrumentos de proteção disfarçada à determinados setores, pois podem onerar insumos intermediários importados ao bloco, afetando a relação de preços e a competitividade entre produtos no interior do bloco. ${ }^{38}$

Assim, regras de origem muito restritivas podem causar um efetivo aumento do protecionismo face a insumos oriundos de terceiros países não membros do Acordo, ainda que as tarifas externas não tenham sido alteradas. ${ }^{39} \mathrm{E}$, simultaneamente, incentivar o comércio de insumos de fontes no interior do bloco, ainda que estas sejam menos eficientes economicamente. ${ }^{40}$ Desse modo, as regras de origem são frequentemente utilizadas de forma estratégica, de modo a resguardar determinados setores dos efeitos da formação de um Acordo Regional. ${ }^{41}$ De fato, regras de origem podem ser instrumentos de seletividade, com os adicionais problemas de falta de transparência e aumento nos custos de transação.

Retomando o raciocínio de Baldwin, a existência de um emaranhado complexo de Acordos Regionais, já identificado como síndrome do spaguetti bowl, se caracteriza pela existência de regras de origem diferentes e não harmonizadas, consequência dos interesses específicos de grupos de pressão influentes em cada economia nacional. ${ }^{42}$ Exatamente pelo efeito distorcivo que elas podem gerar, as regras de origem deveriam ser cuidadosamente negociadas, e principalmente monitoradas, pelo sistema multilateral com vistas à garantir que não constituam um entrave abusivo ao comércio de terceiros Estados com os membros dos blocos.

No que se refere ao segundo elemento, cumulação é um termo técnico que designa o sistema pelo qual países que possuem as mesmas regras de origem permitam que produtos originados em um primeiro país sirvam de insumos a serem processados e/ou adicionados em um outro país, sem que isso afete o status do produto final como originário do segundo país. São, assim, instrumentos adotados em complementariedade às regras de origem, objetivando corrigir eventuais distorções das regras de origem no

37 MOTA, Pedro Infante. O Sistema GATT/OMC: Introdução Histórica e Princípios Fundamentais. Coimbra: Almedina, 2005. p. 568-569.

38 KRISHNA, Kala. Understanding Rules of Origin. NBER Working Paper Series. Working Paper n. 11.150. Cambridge: National Bureau of Economic Research, 2005. p. 1.

39 HOEKMAN, Bernard. KOSTECKI, Michel. The Political Economy of the World Trading System: from GATT to WTO. Oxford: Oxford University Press, 1995. p. 227.

40 KRISHNA, Kala. op. cit., p. 4.

41 KRISHNA, Kala. op. cit.. p. 6.

42 BALDWIN, Richard. op. cit. nota 34. 
fluxo concreto do comércio internacional de bens manufaturados, e permitindo uma flexibilização necessária na aplicação das regras de origem.

A cumulação é comumente classificada como bilateral, diagonal e total. A cumulação bilateral se dá entre dois países partes de acordos que permitam a cumulação entre eles, beneficiando produtos ou materiais originários, é praticado em basicamente todos os regimes de origem. ${ }^{43}$ A cumulação diagonal, por sua vez, se opera entre mais de dois países, permitindo que o processo de transformação manufatureira envolva múltiplos países, sendo considerado para fins de origem do produto final o último país no qual foi realizada uma operação relevante de processamento. ${ }^{44}$ A cumulação total, por fim, somente se dá em Uniões Aduaneiras, pois pressupõe um grupo de países que tenham as mesmas regras de origem e tarifas externas comuns. É um passo adiante da cumulação diagonal, e assim como esta tem a capacidade de ampliar consideravelmente o escopo de aplicação das regras de origem. ${ }^{45}$

Observa-se, pois, que a cumulação bilateral é instrumento de maior restrição ao fluxo de comércio de insumos oriundos de terceiros países no bloco, ao passo que a cumulação diagonal e a cumulação completa permitem uma maior abrangência de produtos cobertos pelo regime de regras de origem, e portanto reduzem o efeito distorcivo e a utilização protecionista das regras de origem. Há, desse modo, uma progressão do acesso de insumos ao mercado regional, na passagem de uma cumulação a outra, respectivamente. ${ }^{46}$

Retomando o raciocínio de Baldwin, o Autor identifica que a existência de um emaranhado complexo de Acordos Regionais, síndrome do spaguetti bowl, se caracteriza também pela existência de regras de cumulação bilateral, ao passo que essas permitem uma aplicação mais restritiva dos sistemas de regras de origem e a consequente distorção do padrão de consumo de insumos intermediários. ${ }^{47}$ Resta claro que medidas de multilateralização devem substituir a cumulação bilateral pelos demais tipos. Diante das maiores complexidades da cumulação completa, o autor propõe, portanto, a adoção de cumulação diagonal, como modo de impedir que as regras de origem exerçam influência nas escolhas de fornecedores entre os Estados membros da zona de cumulação, e os

43 ESTEVADEORDAL, Antoni; SUOMINEN, Kati. Rules of Origin: A World Map and Trade Effects. Integration, Trade and Hemispheric Issues Division, Integration and Regional Programs Department, InterAmerican Development Bank Paper. Preparado para apresentação na $7^{\mathrm{a}}$ Annual Conference on Global Economic Analysis: Trade, Poverty, and the Environment - The World Bank, Washington, 17-19 jun. 2004. Disponível em: <https://www.gtap.agecon.purdue.edu/resources/download/1866.pdf> Acesso em: 30 jun. 2013. p. 5.

44 ESTEVADEORDAL, Antoni; SUOMINEN, Kati. Ibid.

45 ESTEVADEORDAL, Antoni; SUOMINEN, Kati. Ibid.

46 ESTEVADEORDAL, Antoni; SUOMINEN, Kati. Ibid.

47 BALDWIN, Richard. op. cit, nota 34. p. 1.481. 
permitam, portanto, realizar a escolha mais eficiente. Nessa questão novamente há espaço para a coordenação pelo sistema multilateral de comércio.

\subsection{Experiências concretas de multilateralização}

Para basear empiricamente suas proposições, Baldwin cita duas experiências históricas como exemplos de multilateralização do regionalismo: o Sistema Pan-Europeu de Cumulação (Pan-European Cumulation System - PECS) e o Acordo de Tecnologia da Informação (Information Technology Agreement - ITA), que brevemente reportamos com o objetivo de vislumbram em concreto possibilidades de implementação deste paradigma.

O Sistema Pan-Europeu de Cumulação (PECS) foi formulado, em 1997, como instrumento de sanar os malefícios oriundos de uma variedade de regras de origem e de cumulação desconexas, pertencentes a um emaranhado de Acordos Preferenciais dos quais a UE fazia parte. É que, como observado anteriormente, regras de origem restritivas, e/ou com critério de cumulação somente bilateral, podem ter um efeito de desvio de comércio ao impedir que o produtor no interior do bloco faça a escolha de fornecedor mais eficiente. E, embora possam impulsionar a demanda intrarregional pelo insumo, favorecendo por certo prazo determinados setores da produção, a crescente desagregação da cadeia produtiva torna cada vez mais limitados os setores que se beneficiam desse quadro.

Ademais, a existência de diferentes sistemas de regras de origem e cumulação torna mais difícil e oneroso às firmas organizar sua cadeia internacional de fornecedores. ${ }^{48}$ Ambas as questões, em uma matriz de produção globalizada com crescente fragmentação das etapas produtivas, tornaram os efeitos econômicos do spaguetti bowl indesejáveis à maior parte dos produtores, o que inverteu o jogo de pressões políticas na UE. ${ }^{49}$ Desse modo, produtores da União Europeia (UE), ainda que tivessem em um primeiro momento incentivado o emaranhado do spaghetti bowl, passaram a pressionar por mudanças na UE, que promovessem uma melhor acomodação de seus interesses de eficiência econômica, e uma consequente multilateralização de seus compromissos regionais e ampliação do número de parceiros comerciais com acesso ao mercado comunitário. ${ }^{50}$

48 GASIOREK, Michael; AUGIER, Patricia; LAI-TONG, Charles. Multilateralizing Regionalism: Lessons from the EU Experience in Relaxing Rules of Origin. Chapter 4. In: BALDWIN, Richard; LOW, Patrick. Multilateralizing Regionalism: Challenges for the Global Trading System. Cambridge: Cambridge University Press. 2009. p. 155.

49 BALDWIN, Richard. op. cit. nota 34.

50 BALDWIN, Richard; EVENETT, Simon; LOW, Patrick. Multilateralizing Non-Tafiff RTA Commitments. In: BALDWIN, Richard; LOW, Patrick. Multilateralizing Regionalism: Challenges for the Global Trading System. Cambridge: Cambridge University Press, 2009. p. 87. 
A União Europeia promoveu, então, através da constituição do PECS duas mudanças principais: (1) a harmonização de regras de origem, para evitar os custos de preencher os requisitos de documentação de diferentes sistemas de origem; e (2) a permissão de cumulação diagonal, que amplia as fontes de insumos para aquelas localizadas em toda a área do PECS sem ameaçar o status do produto final como originário da União. ${ }^{51}$

O ITA, por sua vez, foi formulado plurilateralmente sob os auspícios da OMC, em face do mercado de tecnologia da informação, que se encontrava envolto por um emaranhado de liberalizações unilaterais, regionais e multilaterais, entretanto a cumulação bilateral e regras de origem não-harmonizadas afastavam o setor da situação real de livre comércio. O ITA possui características distintivas e é considerado um sucesso de normatização setorial, vez que estabeleceu tarifas zero em ampla cobertura de produtos estabelecidos previamente, sob o Princípio da Nação Mais Favorecida, e com cronograma de reduções previamente acordado e implementado. ${ }^{52}$

O ITA foi criado por iniciativa dos EUA, com o posterior apoio da UE e Japão, tendo como claro objetivo o estabelecimento do livre comércio no setor. De fato, o Acordo previa que somente entraria em vigor caso os signatários completassem uma fatia de $90 \%$ do comércio mundial no setor, o que veio a ser atingido em 1997 com mais algumas ratificações. Segundo Baldwin, teria havido uma situação de efeito dominó, que poderia ser implementada em demais setores. ${ }^{53}$

Assim como a inversão no jogo de interesses dos produtores tende a pressionar por uma homogeneização e relaxamento nas regras de origem, Baldwin tira da experiência do ITA a conclusão de que liberalizações multilaterais setoriais promovidas pelos principais players do comércio internacional criam um efeito dominó que incentiva os demais a participarem da iniciativa multilateralizante. O problema, contudo, melhor abordado em outro trabalho, consiste na análise dos limites e condições nas quais esses atores tem promovido estas liberalizações em âmbito regional, de modo a impor regras que lhe sejam evidentemente favoráveis. ${ }^{54}$

O Autor retoma, portanto, sua previsão de existência de três grandes polos de emaranhados de Acordos Regionais, a partir da Europa, América do Norte e Ásia, três grandes blocos comerciais, para afirmar que pode haver uma tendência semelhante ao ITA, na qual as forças políticas de seus epicentros pressionariam pela celebração de acordos de liberalização setorial multilateral. E assim, a tendência à inversão dos interesses políticos

\footnotetext{
51 GASIOREK, Michael; AUGIER, Patricia; LAI-TONG, Charles. op. cit., p. 156-166.

52 MANN, Catherine; LIU, Xuepeng. The Information Technology Agreement: Sui Generis or Model Stepping Stone? In: BALDWIN, Richard; LOW, Patrick. Multilateralizing Regionalism: Challenges for the Global Trading System. Cambridge: Cambridge University Press, 2009. p. 182.

53 BALDWIN, Richard. op. cit nota 34.

54 HORN, Henrik; MAVROIDIS, Petros C.; SAPIR, André. op. cit.
} 
e à posterior multilateralização seria processo capaz de levar a ordem econômica ao livre comércio, a partir do protagonismo destes três epicentros, e o exercício de seu papel como facilitador do livre comércio.

É explícito, ainda, que os dois exemplos de multilateralização do regionalismo trazidos à baila pelo seu entusiasta se contrastam quanto ao papel da OMC. Se o ITA foi resultado de negociações conduzidas na sistemática da OMC, o PECS foi concebido, negociado e implementado por uma das hegemonias do comércio internacional, a União Europeia. Embora seja impossível generalizar a partir destas duas experiências, acredita-se que o envolvimento da OMC resultou numa multilateralização do regionalismo de maneira mais aberta e menos hegemônica. ${ }^{55}$

Por fim, de forma mais geral, a partir do paradigma de multilateralização sob análise é possível indicar outras maneiras que capazes de promoverem a multilateralização dos esquemas regionais, e o seu consequente aproveitamento pelo sistema multilateral de comércio. Citam-se a esse respeito, as seguintes medidas que de modo geral possam contribuir para a concretude da multilateralização: (a) a expansão geográfica dos ARC, ou de um conjunto de medidas aplicadas; (b) a inclusão em ARC de disposições da regra da Nação Mais Favorecida no que tange a determinados setores e medidas; (c) regras acordadas em ARC que tornem na prática a discriminação indesejável ou inviável; (d) a inclusão de clausula da Nação Mais Favorecida em relação a terceiros, que garantam aos signatários de Acordos existentes a manutenção dos seus benefícios quando da formação de ARC subsequentes; (e) a inclusão de disposições que previnam que ações permitidas sob a disciplina dos Acordos da OMC sejam consideradas tratamento discriminatório. ${ }^{56}$

\section{Conclusão}

Para além do paradigma da multilateralização do regionalismo, que entendemos ser teoria de lucidez e relevância, estão sendo desenvolvidas outras perspectivas, que também se afastam do enfoque direto na relação econômica entre o sistema multilateral e os Acordos Regionais, e buscam centralizar-se no aspecto da construção da normatividade e da formulação de esquemas regulatórios nas relações econômicas internacionais.

Baldwin complementa sua teoria da multilateralização do regionalismo, com um estudo no qual, após evidenciar novas complexidades da relação entre o multilateralismo e o regionalismo, clama por um novo quadro regulatório do comércio

\footnotetext{
55 BALDWIN, Richard. op cit. nota 34.

56 BALDWIN, Richard; EVENETT, Simon; LOW, Patrick. op. cit., p. 81.
} 
internacional. O nexo entre (i) comércio, (ii) investimentos e (iii) serviços passou a ser elemento central e característica distintiva do comércio internacional no século XXI. ${ }^{57}$

Como consequência, as principais barreiras ao comércio neste século não as tarifárias, mas aquelas relacionadas à defesa da concorrência, trânsito de capitais, direitos de propriedade intelectual, e segurança de investimentos. ${ }^{58}$ São temas que já foram implementados no interior dos Estados desenvolvidos, mas ainda necessitam de regulamentação doméstica nos demais Estados. O regionalismo atual passa a preencher, através de Acordos Regionais "profundos", o espaço de regulamentação desses temas, juntamente com reformas unilaterais e Tratados Bilaterais de Investimentos. ${ }^{59}$

Nessa perspectiva, toda a sistemática de negociação - regional ou multilateral- passa a circular não mais em função de barganhas para o acesso a mercados através de cortes tarifários, mas em torno da capacidade de expansão do modelo regulatório ao qual um polo já esteja vinculado. A função dos grupos de interesse interno assume força determinante da política comercial, ao exercer influência substancial sob as negociações nas diferentes esferas - multilateral, regional e unilateral. ${ }^{60}$

É assim também que Thorstensen propõe uma visão integrada da regulação do comércio global, que passaria por uma análise transversal das dimensões normativas relacionadas ao comércio internacional, visando a melhor compreensão dos efeitos cruzados entre o sistema multilateral-plurilateral, os sistemas preferenciais, e os sistemas nacionais de comércio externo. ${ }^{61}$

A Autora também destaca a relevância central de uma análise atenta do mapeamento dos acordos preferenciais negociados por um certo parceiro, uma vez que a concentração de países com acordos em torno de um eixo evidencia padrões de regras que depois serão levadas às instâncias multilaterais. E assim, se um número significativo de países adotarem certo modelo regulatório, o grau de liberdade possível para a negociação multilateral ou a posterior inclusão de outros países no grupo será limitada. ${ }^{62}$

Diante do diagnóstico da polarização entre os Acordos Regionais sob os eixos norte-americano e europeu, a partir de seus respectivos moldes e interesses, ${ }^{63}$ há um chamamento à participação mais efetiva e consciente dos países emergentes, e destacamos - do Brasil - na construção dessa arquitetura institucional regulatória, pois a normatividade que hoje parece diluída tende a se cristalizar, exatamente devido à

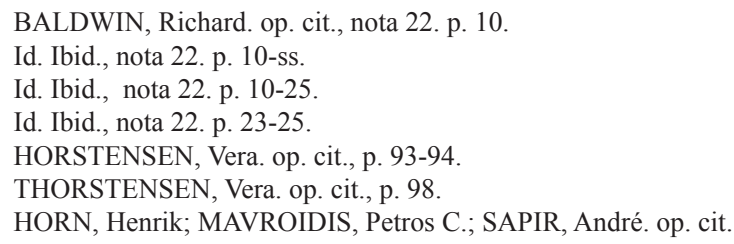


tipologia dos compromissos abarcados, que importam implicações jurídico-institucionais domésticas duradouras.

O novo desafio que o regionalismo coloca, portanto, ao sistema multilateral é sutil, ao ameaçar a legitimidade do sistema em sua capacidade de congregar distintos interesses e construir entendimentos. Nesse sentido, não se trata apenas de promover a multilateralização do regionalismo, mas de que maneira isto será concretizado. A multilateralização de um modelo hegemônico, que favoreça apenas os Estados desenvolvidos parece se distanciar dos objetivos globais que vislumbramos no sistema multilateral de comércio. Esses objetivos não se limitam à promoção do livre comércio, mas incluem a manutenção da paz, promoção do desenvolvimento econômico e bem-estar mundial, o alcance do desenvolvimento sustentável e a proteção ambiental, a redução da pobreza e a gerência de crises econômicas globais. ${ }^{64}$

Peña vislumbra três cenários possíveis ao futuro da OMC, levando em consideração o quadro aqui explicitado. O primeiro deles seria a inércia institucional, com a manutenção dos tradicionais métodos de trabalho e da mesma agenda, fatalmente fixada da Rodada Doha. O segundo cenário seria de reforma institucional profunda, o estabelecimento de "um novo Bretton Woods", que enfrentaria, contudo, dificuldades diante da atual distribuição do poder mundial. O terceiro cenário, em tom intermediário aos dois extremos, seria de metamorfose da instituição, de modo a aproveitar os consensos acumulados e considerados eficazes, mas incluindo novos temas na mandato negocial. ${ }^{65}$

A metamorfose da OMC, portanto, pressupõe uma disposição a trazer estes temas para discussão como foco central, como integradores da complexidade da agenda do comércio internacional, que não se pode ignorar. Acreditamos, assim, nesta metamorfose- possível e necessária, na qual o Mecanismo de Solução de Controvérsias da organização assume relevância central.

Por um lado, o mecanismo de solução de controvérsias constitui diferencial significativo - que estimularia os estados a trazerem as negociações à $\mathrm{OMC}$, sob o aspecto da jurisdicionalização dos compromissos, e de sua habilidade de promover o cumprimento de suas normas. ${ }^{66}$ Por outro lado, o mecanismo tem responsabilidade vital no balanceamento entre os diferentes valores da sociedade internacional, e por meio de

${ }^{64}$ JACKSON, John. H. Sovereignty, the WTO, and Changing Fundamentals of International Law. Cambridge: Cambridge University Press. 2006. p. 86.

65 PEÑA, Felix. Entre Doha, el cambio y la fragmentacion: hacia donde va la OMC? Programa de Cátedras de la OMC, FLACSO. Abr. 2012. Disponível em: http://catedraomc.flacso.org.ar/wp-content/uploads/2012/05/ Felix-Pe\%C3\%B1a-Doha-Fragmentaci\%C3\%B3n.pdf. Acesso em: 30 jun. 2013.

66 BRADFORD, Anu. When the WTO Works, and How It Fails. Virginia Journal of International Law. v. 51, p. 1-56, 2010-2011. p. 38-45, 53. 
sua atividade interpretativa, determina os contornos concretos da já existente abertura axiológica a certos temas. ${ }^{67}$

Por fim, não se pode ignorar que a eleição de um desses cenários, bem como a crença nos limites e possibilidades de resposta da Organização Mundial do Comércio aos desafios do regionalismo, depende diretamente da abordagem que conferirmos à ontologia institucional desta organização e à sua função no sistema jurídico internacional.

São Paulo, março de 2013.

\section{Referências}

AMARAL JÚNIOR, Alberto do. A solução de controvérsias na OMC. São Paulo: Atlas, 2008.

BALDWIN, Richard. 21th Century Regionalism: Filling the gap between 21th century trade and 20th century rules. World Trade Organization, Economic Research and Statistics Division. Staff Working Paper ERSD-2011-08, mai. 2011.

BALDWIN, Richard; EVENETT, Simon; LOW, Patrick. Multilateralizing Non-Tariff RTA Commitments. In: BALDWIN, Richard; LOW, Patrick. Multilateralizing regionalism: Challenges for the Global Trading System. Cambridge: Cambridge University Press, 2009.

BALDWIN, Richard. Multilateralizing regionalism: Spaguetti Bowls as Building Blocs on the Path to Global Free Trade. The World Economy. v. 29, n. 11, p. 1451-1518, 2006.

BERGSTEN, Fred. Open Regionalism. The World Economy. v. 20, n. 5, p. 545-565, ago. 1997.

BHAGWATI, Jagdish. Preferential Trade Agreements: the Wrong Road. Law and Policy in International Business. v. 27, p. 865-90, 1996.

BRADFORD, Anu. When the WTO Works, and How It Fails. Virginia Journal of International Law, v. 51, p. 1-56, 2010-2011.

CELLI JUNIOR, Umberto. Teoria Geral da Integração: em Busca de um Modelo Alternativo. In: MERCADANTE, Araminta de Azevedo; JUNIOR, Umberto Celli; ARAÚJO, Leandro Rocha de. Blocos Econômicos e Integração na América Latina, África e Ásia. Curitiba: Juruá, 2003.

CELLI JUNIOR, Umberto et al. MERCOSUR in South-South Agreements: in the middle of two models of regionalism. UNCTAD Virtual Institute, USP - FLACSO Joint Research Project Analysis of South-South Cooperation in Trade, set. 2010. Disponível em: $<$ http://www.iadb.org/intal/intalcdi/ PE/2011/08164.pdf >. Acesso em: 30 jun. 2013.

$\overline{67}$ AMARAL JÚNIOR, Alberto do. op. cit., 251-282. 
CEPAL. Regionalismo Abierto: un Examen del Concepto a la Luz de las Experiencias de América Latina y Asia y el Pacífico. In: Panorama de la Inserción internacional de América Latina y el Caribe. LC/G.2085-P. Santiago: Naciones Unidas, 2001.

DEVLIN, Robert; ESTEVADEORDAL, Antoni. What's New in the New Regionalism in the Americas? In: BULMER-THOMAS. Victor. (ed). Regional integration in Latin America and the Caribbean: The Political Economy of Open Regionalism. London: Institute of Latin American Studies, University of London, 2001. cap. 1.

ESTEVADEORDAL, Antoni; SUOMINEN, Kati. Rules of origin: a world map and trade effects. Integration, Trade and Hemispheric Issues Division, Integration and Regional Programs Department, Inter-American Development Bank Paper. Preparado para apresentação na $7^{\mathrm{a}}$ Annual Conference on Global Economic Analysis: Trade, Poverty, and the Environment - The World Bank, Washington, 17-19 jun. 2004. Disponível em: <https://www.gtap.agecon.purdue.edu/resources/download/1866. pdf>. Acesso em: 30 jun. 2013.

ENTENDIMENTO sobre a Interpretação do Artigo XXIV. Versão oficial em português dada pelo Decreto Legislativo n. 1.355, de 30 de Dezembro de 1994. Disponível em: <http://www.planalto. gov.br/ccivil_03/decreto/Antigos/D1355.htm>. Acesso em: 30 jun. 2013.

FAWCETT, Louise. Regionalism in Historical Perspective. In: FAWCETT, Louise; HURRELL, Andrew. Regionalism in World Politics. Oxford: Oxford University Press, 1995.

FIORENTINO, Roberto; VERDEJA, Luis; TOQUEBOEUF, Christelle. The changing landscape of regional trade agreements: 2006 Update. WTO Discussion Paper n. 12. Geneva: WTO, 2007.

GATT. Versão oficial em português dada pelo Decreto Legislativo n. 1.355, de 30 de Dezembro de 1994. Disponível em: <http://www.planalto.gov.br/ccivil_03/decreto/Antigos/D1355.htm>. Acesso em: 30 jun. 2013.

GATS. Versão oficial em português dada pelo Decreto Legislativo n. 1.355, de 30 de Dezembro de 1994. Disponível em: <http://www.planalto.gov.br/ccivil_03/decreto/Antigos/D1355.htm>. Acesso em: 30 jun. 2013.

GASIOREK, Michael; AUGIER, Patricia; LAI-TONG, Charles. Multilateralizing Regionalism: Lessons from the EU Experience in Relaxing Rules of Origin. In: BALDWIN, Richard; LOW, Patrick. Multilateralizing Regionalism: Challenges for the Global Trading System. Cambridge: Cambridge University Press. 2009.

HOEKMAN, Bernard. KOSTECKI, Michel. The political economy of the world trading system: from GATT to WTO. Oxford: Oxford University Press, 1995.

HORN, Henrik; MAVROIDIS, Petros C.; SAPIR, André. Beyond the WTO? An anatomy of EU and US preferential trade agreements. Bruegel Blueprint Series. Brussels: Bruegel, 2009. v. 7.

HURRELL, Andrew. On global order: power, values and the constitution of international society. New York: Oxford University Press, 2007. 
JACKSON, Jonh H. The jurisprudence of GATT and the WTO. Cambridge: Cambridge University Press, 1. ed. 2000.

JACKSON, John. H. Sovereignty, the WTO, and Changing Fundamentals of International Law. Cambridge: Cambridge University Press. 2006, p. 98.

KRISHNA, Kala. Understanding Rules of Origin. NBER Working Paper Series. Working Paper n. 11.150. Cambridge: National Bureau of Economic Research, 2005.

LAFER, Celso. Comércio, Desarmamento e direitos humanos: reflexões sobre uma experiência diplomática. São Paulo: Paz e Terra, 1999.

MANN, Catherine; LIU, Xuepeng. The information technology agreement: sui generis or model stepping stone? In: BALDWIN, Richard; LOW, Patrick. Multilateralizing regionalism: challenges for the global trading system. Cambridge: Cambridge University Press, 2009.

MANSFIELD, Edward D.; MILNER, Helen V. The political economy of regionalism. New York: Columbia University Press, 1997.

MAVROIDIS, Petros. If you don't do someone else will (or won't): testing compliance of preferential trade agreements with the multilateral rules. Journal of World Trade. v. 40, n. 1, p. 187-214, 2006.

MOTA, Pedro Infante. O sistema GATT/OMC: introdução histórica e princípios fundamentais. Coimbra: Almedina, 2005.

PEÑA, Felix. Entre Doha, el cambio y la fragmentacion: hacia donde va la OMC? Programa de Cátedras de la OMC, FLACSO. Abr. 2012. Disponível em: <http://catedraomc.flacso.org.ar/wpcontent/uploads/2012/05/Felix-Pe\%C3\%B1a-Doha-Fragmentaci\%C3\%B3n.pdf $>$. Acesso em: 30 jun. 2013.

PRAZERES, Tatiana Lacerda. A OMC e os blocos regionais. São Paulo: Aduaneiras, 2008.

SILVA, Roberto Luiz. Direito comunitário e da integração. Porto Alegre: Ed. Síntese, 1999.

THORSTENSEN, Vera. O multissistema da regulação do comércio global: proposta de novo referencial teórico e nova metodologia de análise. Revista Tempo do Mundo: Instituto de Pesquisa Econômica Aplicada, Brasília, v. 3, n. 1, 2011.

VINER, Jacob. The customs union issue. Washington DC: Anderson Kramer Associates, 1961.

WTO. Differential and more favourable treatment, reciprocity and fuller participation of developing countries. L/4903 - 1979. Decisão de 28 de Novembro de 1979. 